\title{
A FENOMENOLOGIA E A FORMAÇÃO HUMANA NA PERSPECTIVA DE EDMUND HUSSERL
}

The Phenomenology and Human Education in Edmund Husserl's Perspective

La Fenomelogía y formación Humana em Perspectiva de Edmund Husserl

\section{Carlos Cardoso Silva ${ }^{* 1}$}

${ }^{1}$ Universisade Federal de Goiás, Faculdade de Educação, Goiânia - Goiás, Brasil.

*Correspondência: Avenida Brasília, 641 - Qd. 19 - Lt. 17 - Jardim São Salvador-Trindade - Goiás,

Brasil. CEP: 75.388-472. E-mail: carlos.cardoso27@gmail.com

\section{RESUMO}

O artigo discute a Fenomenologia e a Formação Humana na perspectiva de Edmund Husserl. É uma reflexão a partir do termo fenomenologia, onde procura compreensão do sentido e do significado do fenômeno, apontando que uma das principais preocupações da fenomenologia como método é evidenciar as estruturas em que a experiência ocorre, é deixar transparecer na descrição das experiências as suas estruturas universais. Apresenta as categorias de intencionalidade e epochê visando o conhecimento, onde todo ato de conhecimento (noema) corresponde a certa modalidade de consciência (noesis). Apresenta também, a categoria do Lebenswelt (o mundoda-vida) fundamental e significativa para Husserl em toda a sua trajetória como homem e pesquisador rigoroso, discute a crise da humanidade europeia e a formação humana, uma contribuição para a educação problematizar os atuais problemas enfrentados pela humanidade.

Palavras-chave: fenomenologia, formação humana, educação.

\section{ABSTRACT}

This essay discusses the Phenomenology and Human Formation according to Edmund Husserl's perspective. It is a reflection of use of the term "phenomenology', which provides the understanding of the meaning and significance of the phenomenon. It also points out that a major concern in phenomenology as method is to evidence the structures in which the experience occurs. Phenomenology must disclose, in the description of the experiences, the universal structures where they are based. It presents the categories of intentionality and epoche and the essay looks foward to the aknowledgement of every act of knowledge (noema) and its correspondence to an specific mode of consciousness (noesis). It also presents the husserlian category of Lebenswelt (the world-of-life), which is a fundamental and significant conception for Husserl throughout his career as a man and rigorous researcher. The text discusses the European humanity and human crisis and it offers a contribution to problematize education and current problems faced by humanity.

Keywords: phenomenology, human development, education.

\section{RESUMEN}

Ese artículo discute la fenomenología y el desarollo humano de acuerdo con la perspectiva de Edmund Husserl. Es un reflejo del concepto de la fenomenología, que busca la comprensión del significado y importancia del fenómeno. También señala que una de las principales preocupaciones de la fenomenología como método consiste en revelar la descripción de las experiencias y mostar las estructuras universales en que están basadas. El texto presenta las categorías de intencionalidad y epoche en la búsqueda del conocimiento, donde cada acto de conocimiento (noema) se relaciona al modo correcto de la conciencia (noesis). También se muestra la categoría de Lebenswelt (mundo-de-la-vida) fundamental y significativa para Husserl al largo de su carrera como un hombre e 
investigador riguroso. El artículo analiza la crisis de la humanidad europea y del próprio hombre, presentando una contribución a fin de problematizar la educación y los problemas actuales que enfrenta la humanidad.

Palabras clave: fenomenología, el desarrollo humano, la educación.

\section{INTRODUÇÃO}

A expressão fenomenologia (phainómenon + logos) vem do grego, do verbo phaíno que significa brilhar, fazer-se visível, aparecer, mostrar-se. Phainómenon é o que aparece, é visível, se mostra. O verbo lego (infinitivo: légein), também do grego, possui vários significados: juntar, contar, enumerar, dizer, declarar, anunciar, designar, escolher, ler, refletir, pensar.

O substantivo logos, originário desse verbo, significa palavra, o que é dito, discurso, revelação divina, resposta de um oráculo, máxima, ordem, matéria de estudo ou de conversação, argumento, pensamento, inteligência, juízo, explicação, estudo, razão ou valor de uma coisa, justificação. Portanto, logos é o que permite ver, oferece razão, o sentido, a natureza, a causa, o fundamento de alguma coisa (HEIDEGGER, 1989).

Compreendendo e interpretando o sentido e o significado do fenômeno, o mundo fenomenológico se evidencia, aparece (BICUDO, 1999). Etimologicamente, fenomenologia é o estudo ou a ciência do fenômeno. Entendendo-se fenômeno como aquilo que aparece e se mostra por si mesmo e logos como discurso esclarecedor, temos fenomenologia como sendo o discurso esclarecedor daquilo que se mostra por si mesmo. Procura-se abordar diretamente o fenômeno, interrogá-lo e descrevê-lo, numa tentativa de captar a sua essência (MARTINS, 1992).

Uma das principais preocupações da fenomenologia como método é evidenciar as estruturas em que a experiência ocorre, é deixar transparecer na descrição das experiências as suas estruturas universais. De acordo com Husserl
(2000), os fenômenos são os atos e os correlatos dessa consciência vividos pela consciência. Assim, Husserl apresenta as categorias da fenomenologia que contribuem para melhor apreensão do fenômeno, dentre as quais destacamos: a intencionalidade, a epoché e a redução eidética. $\mathrm{O}$ autor esclarece que uma das ideias principais da fenomenologia é a de que "toda consciência é consciência de alguma coisa".

Trata-se de uma intencionalidade da consciência que se define na medida em que visa ao objeto. Assim, "a intencionalidade significa apenas esta particularidade intrínseca e geral que a consciência tem de ser consciência de qualquer coisa, de trazer, na sua qualidade de cogito, o seu cogitatum em si próprio" (HUSSERL, 2000, p. 48). De outra forma, a todo conteúdo visado, a todo ato de conhecimento (noema) corresponde a certa modalidade de consciência (noesis).

Em relação à suspensão provisória de juízos, ou epoché, Husserl esclarece que essa suspensão é uma forma de apreensão do fenômeno como ele realmente é e não da forma como dizem que ele é, ou seja, é uma atitude desvinculada de qualquer interesse natural ou psicológico no modo de ser da existência das coisas do mundo. Com a epoché, diz Husserl:

[...] pela epoché fenomenológica, reduzo o meu eu humano natural e a minha vida psicológica - domínio da minha experiência psicológica interna - ao meu eu transcendental e fenomenológico, domínio da experiência interna transcendental e fenomenológica. (HUSSERL, 2000, p. 39).

Ainda por meio da epoché, isto é, por meio da suspensão de juízos, Husserl afirma: 
[...] esse momento chave que ao menos uma vez na vida devem viver aquelas pessoas que querem reconhecer-se como filósofos. Ou seja, a epoché trata de pensar o trânsito da vida ordinária à vida filosófica, o que significa que a epoché significa realmente o começo da filosofia [...] (MARTIN, 2003, p.14).

Segundo Husserl (2000, p. 20), essa suspensão é fundamental para a compreensão do fenômeno: "a epoché filosófica, que nos propusemos praticar, deve consistir, formulando-o expressamente, em nos abstermos por completo de julgar acerca das doutrinas de qualquer filosofia anterior e em levar a cabo todas as nossas descrições no âmbito desta abstenção".

Já redução eidética, segundo Husserl, é uma decorrência da epoché, uma forma de descrição dos fenômenos como eles são, isto é, no seu estado "primitivo", anterior a qualquer interpretação. Neste sentido, a redução eidética é um desvendar, um pôr a descoberto, um desentranhar o fenômeno para além da sua aparência. Uma vez suspensos os pré-conceitos (epoché), a redução eidética (descrição) e tendo-se clareza de que toda consciência é intencionalidade, faz-se necessário um trabalho de interpretação (hermenêutica) para apreender os significados do fenômeno. Essa tarefa interpretativa consiste em decifrar o sentido aparente, em explicitar os sinais de significação. Para a fenomenologia, todo fenômeno está relacionado com o mundo humano, por isso, todo fenômeno é uma multiplicidade de significados.

Como se pode constatar, semelhante descrição do fenômeno diz respeito, diretamente, ao sujeito humano e ao sentido de sua existência. Se, no fenômeno, o que está em questão é o sentido, este aparece como sendo, antes de tudo, o do homem em função de sua existência. Mas, se se trata do sentido da existência, não poderemos falar do sujeito humano em sentido abstrato, e sim, de maneira engajada com referência explícita ao mundo. A fenomenologia da existência surge da dialética entre o homem e o mundo, na interação da existência com o mundo, tal como vivida na experiência da intencionalidade.

A palavra fenômeno, em sua etimologia, como vimos, quer dizer aparecimento, manifestação. Não se trata das aparências como, às vezes, apressadamente se diz. Trata-se da experiência em que aparece ao homem, à sua consciência, como o mundo, a cultura, o sentido, isto é, em que algo se possibilita a conhecer. Dessa forma, Heidegger (1989) afirma que o fenômeno nos remete à questão da verdade (alétheia), cuja etimologia grega significa desvelamento, desocultamento. A experiência fenomenológica é, precisamente, a do ser no mundo. É o que nos incita a dizer que o fenômeno aparece como uma estrutura, isto é, como uma multiplicidade significativamente unificada por meio das relações características dessa mesma estrutura. Nesse sentido, Capalbo (1996, p. 19) afirma:

Não nos é possível separar o fenômeno e coisa em
si. O fenômeno é conhecido diretamente, sem
intermediários, ele é objeto de uma intuição
originariamente doadora. Não há fenômeno que
não seja fenômeno para uma consciência de algo,
não há consciência sem que ela seja consciência de
algo, sem que seja determinada como certa
maneira de visar os objetos, o mundo.

Destarte, podemos dizer que a análise do "serno-mundo" aproxima-nos da compreensão de que o ser humano é um ser histórico. Assim, do ponto de vista da fenomenologia, a história apresenta-se como manifestação do esforço da interação dos homens entre si, e destes, com o mundo. As ideias de Husserl criaram um caminho fecundo para o estudo do comportamento humano, e coube à fenomenologia a tarefa infinita de explicar e compreender a gênese e o 
sentido do mundo e do ser humano. Conforme Zitkoski (1994, p. 101-102),

a pretensão de Husserl fora bastante grande, mas a prudência e a seriedade filosófica não o deixaram cair na ilusão e/ou convencimento ingênuo. A fenomenologia como ciência primeira sempre fora concebida por Husserl como uma tarefa infinita e/ou um ideal que se desenvolveria com a colaboração de sucessivas gerações de filósofos até atingir o grau máximo de racionalidade $\mathrm{e}$ universalidade científicas.

A fenomenologia, portanto, primariamente é um método de evidenciação (entendida no sentido apodítico reflexo-radical), significa, para Husserl, a busca de um fundamento sólido para a filosofia e a ciência, uma ciência radical. Zilles (2002, p. 40 - 41) afirma que Husserl

\begin{abstract}
tenta estabelecer uma filosofia primeira, criando uma ciência fundamental da subjetividade pura. A consciência atuante é este fundamento primeiro de toda a objetividade. Tal filosofia primeira é a fenomenologia como a 'ciência descritiva eidética da consciência pura transcendental' ou a 'doutrina pura descritiva das essências das estruturas imanentes da consciência'. A filosofia tornar-se-á ciência de rigor quando nos fizer tomar consciência de que as construções teóricas do espírito não podem restringir-se à descrição objetivista dos fatos individuais e subsistentes em si mesmos.
\end{abstract}

Portanto, como ciência rigorosa, a fenomenologia demandará do estudioso, do pesquisador, do ser humano, uma atitude fenomenológica que nos guiará às raízes, isto é, às origens últimas de todas as coisas. Segundo Zilles (2002, p. 41), "na fase da crise, Husserl busca este fundamento, de alguma forma, no mundo da vida (Lebenswelt)". Esse pressuposto é basilar para o pensador na constituição de sua teoria.

\section{O LEBENSWELT: O MUNDO DA VIDA}

A categoria do Lebenswelt é fundamental e significativa para Husserl em toda a sua trajetória como homem e pesquisador rigoroso; porém, a partir de 1934 - 1937 sua preocupação com essa categoria se intensificou; esse período, em que se dedicou a estudar a crise da modernidade, Husserl chamou de: $A$ Crise da Humanidade Europeia e a Filosofia. Ele entendeu que a crise tinha como uma das razões a conjuntura em que se encontrava a filosofia. Segundo o autor (2000, p. 22), nas meditações cartesianas:

O estado de divisão no qual se encontra atualmente a Filosofia, a atividade desordenada que ela empreende nos levam a pensar. Do ponto de vista da unidade científica, a filosofia ocidental encontra-se, desde meados do século passado, num visível estado de decadência em relação às épocas precedentes. Por toda parte, desapareceu a unidade: tanto na determinação do objetivo quanto na colocação dos problemas e no método.

Preocupado com esse estado de desordem, Husserl aborda a problemática que, a seu ver, levou à crise. Na sua concepção, a crise se instalou a partir do momento em que houve a matematização da ciência, a aceitação como verdade das repostas dadas pelo método científico, enfim, momento de afastamento do homem do seu mundo-vida, da sua humanidade. Mas, o que significava para Husserl esse mundo-vida que ele denominou de Lebenswelt? O que era para Husserl a denominação de humanidade? Por que a preocupação com essa humanidade, a ponto de dizer que havia uma crise da humanidade europeia?

Segundo esse estudioso, a expressão mundovida remete para uma instância que ultrapassa a dimensão exclusiva da vida biológica; é uma dimensão que rompe com os pressupostos de um conhecimento, de um saber puramente científico. O Lebenswelt para Husserl constitui o horizonte précategorial e originário que foi esquecido pelo mundo que vive uma crise de ordem espiritual. 
Segundo Zilles (1996, p. 48), Husserl entende o Lebenswelt como sendo: "a redução ao mundo da vida, quer dizer, 'colocar entre parênteses' o que se refere a ele [mundo]. Entretanto, a epoché não é o recurso de um idealista escrupuloso, mas o método para o acesso à experiência transcendental por vocação rigorosamente filosófica". Ainda, de acordo com Zilles (2002, p. 48), "por mundo da vida Husserl não entende, pois, o mundo de nossa atitude natural, na qual todos os nossos interesses teóricos e práticos são dirigidos aos entes do mundo. $\mathrm{O}$ mundo da atitude natural era preenchido por interesses teóricos e práticos direcionados ou dirigidos aos entes do mundo".

O mundo da vida é preenchido a partir da atitude fenomenológica que faz a suspensão de nossa atenção no horizonte da atitude natural para ocuparnos unicamente com o próprio mundo da vida, isto é, "como tem lugar para nós a permanente consciência da existência universal, do horizonte universal de objetos reais efetivamente existentes" (ZILLES, 2002, p. 48).

Portanto, o Lebenswelt é o âmbito de nossas originárias "formações de sentido", do qual nascem as ciências. Para Husserl, o mundo da vida é um a priori dado com a subjetividade transcendental, isto é, um horizonte privilegiado do eu transcendental ou puro, enquanto doador de sentido em relação ao eu empírico, mundano, ou seja, uma consciência pura.

Nas suas últimas obras, referindo-se à filosofia, Husserl, com seu rigor, pesquisa atentamente o processo histórico; visualizando a possibilidade de uma perspectiva fenomenológica, analisa que houve um afastamento do ser humano em relação a sua própria humanidade. Mas, o que seria esse afastamento da sua humanidade? Husserl se deparou com questões subjetivas diante do momento tecnicista em que vivia a ciência, devido aos métodos científicos como o psicologismo e o positivismo. Nesse contexto, a ideia de humanidade deveria ser bem esclarecida para não se tornar uma simples divagação metafísica.

Conforme esse autor, a palavra humanidade era utilizada como um discurso vazio de significado, um uso que apenas se referia às relações humanas num campo comum do diálogo. Esse se tornou frágil porque estava sistematizado por hipóteses, opiniões a partir de bases naturais. Era um tema que qualquer pessoa, mesmo desprovida de fundamentação filosófica, utilizava em argumentações sobre essa temática.

A humanidade a que Husserl se referia tratava de uma rigorosa investigação da natureza filosófica sobre a relação, a interação do homem com seu mundo, o qual deveria ser compreendido como todo o horizonte noético-noemático ${ }^{1}$, possível de ser captado nas essências da redução fenomenológica. É justamente na dimensão da captação das essências que Husserl se apresenta como um filósofo rigoroso em busca da constituição do mundo da vida, do lebenswelt, por meio da fenomenologia. Por isso, é importante lembrar que humanidade não são apenas as manifestações afetivas e emocionais que predominam no senso comum, isto é, na atitude natural; humanidade, conforme Husserl (apud Zilles, 2002, p. 43), significa

\begin{abstract}
uma unidade de vida, de uma ação, de uma criação de ordem espiritual, incluindo todos os objetivos, os interesses, as preocupações e os esforços com as instituições e as organizações. Nelas atuam os indivíduos dentro das sociedades múltiplas de diversas complexidades, em famílias, raças, nações, nas quais todos parecem estar interior e espiritualmente vinculados uns aos outros e, como disse, na unidade de uma estrutura espiritual.
\end{abstract}

\footnotetext{
1 Relação sujeito e objeto como uma unidade, não separados como entendia a visão da ciência positivista.
} 
Fazer parte de uma humanidade é colaborar com a cultura; é contribuir para os valores que a constituem; é a fatalidade de todos aqueles que são excelentes e se elevam acima das suas preocupações $\mathrm{e}$ infortúnios individuais, é fazer parte de uma humanitas autêntica. Tudo isto está contido numa análise científica de essência da ideia de uma humanidade racional que conduz a múltiplas investigações particulares que se vão ramificando (FABRI, 2005, p.157 - 172).

$\mathrm{O}$ afastamento da humanidade ocorre a partir do momento que o homem deixa de se preocupar com o fundamento absoluto do viver originário, isto é, deixa de compreender a sua interação homem-mundo na dimensão noético-noemático. Ele passa a viver um relativismo extremo esquecendo-se da existência do ser, isto é, como ser-no-mundo; e como consequência afasta-se do sentido de humanidade. Então, distante da humanidade, resta pouco como referência à mesma. Distanciado, o homem não sabe e não encontra o que buscar. Portanto, fica como se houvesse perdido a sua essência. Em outras palavras, afasta-se do que o torna singular e do que o torna humano.

A preocupação de Husserl com a crise da humanidade europeia, como foi mencionada, estava justamente em esclarecer os equívocos da ciência moderna, na qual as teorias e correntes de pensamento tinham como finalidade uma leitura físico-matemática da realidade e de todo o mundo envolvido. Abrangia, desse modo, tanto a realidade física e natural como a realidade espiritual, ou seja, a realidade humana, com o objetivo de fusão do mundo físico/natural e do mundo do espírito numa única concepção, a saber, a concepção científica. Contrário a essa visão cientificista que o empirismo buscava para a realidade humana, Husserl apresenta as causas e os problemas originados pelo empirismo exagerado e impróprio. Também esclarece as inconvenientes assimilações que a psicologia fez da lógica.

Na obra As Investigações Lógicas, Husserl discorreu sobre o seu tratado de lógica pura e esclareceu a separação entre o ato psíquico e o conteúdo do pensamento. Na quinta investigação (cf. HUSSERL, 1985, 471- 487) apresentou um novo conceito de consciência, ou seja, consciência como intencionalidade. Por ser um estudioso da matemática, percebia os limites que a ciência exata tem para explicar todas as realidades, principalmente a realidade subjetiva, como queriam vários estudiosos que se intitulavam filósofos e que pretendiam propiciar às realidades (física, natural e humana) uma visão exclusivamente por meio da ciência positivista. Husserl afirmava que a matemática como ciência exata e as demais ciências de cunho tecnicista não dariam respostas e nem compreenderiam o campo da humanidade, isto é, o campo do saber humano e do mundo da vida; por isso, ocorreu a crise que a humanidade europeia estava vivendo naquele momento. Esse fato se evidencia na atualidade com o desenvolvimento tecnológico, com a comunicação de massa e o processo de globalização.

A trajetória intelectual de Husserl pode ser concebida em etapas. Para efeito de compreensão é dividida na seguinte ordem, conforme Zilles (1996, p. 14):

Os intérpretes costumam distinguir três etapas no pensamento de Husserl, relacionadas a três de suas principais obras. Fala-se do Husserl das Investigações lógicas caracterizadas por um logicismo essencialista; das Ideias como o idealismo transcendental; da Crise como o vitalismo historicista.

A partir dessas etapas, podemos, de forma simplificada, assim denominar esse autor: primeiro Husserl, segundo Husserl e último Husserl. Na 
terceira etapa, ou na fase do vitalismo historicista, marca-se o seu momento de denúncia com a Crise da Humanidade Europeia e a Filosofia. É significativo ressaltar que, mesmo caracterizado por etapas, o pensamento de Edmund Husserl, apresenta unidade, isto é, existe continuidade no projeto husserliano: explicação oportuna para chamar a atenção de algum espírito mais desavisado ou que pretendesse descaracterizar o projeto do pai da fenomenologia.

De acordo com as mencionadas fases, o pensamento de Husserl, ou melhor, as distintas fases do seu pensamento, de sua intelectualidade, revelaram que o espírito desse pensador era movido e guiado por uma Filosofia Verdadeira. Era evidente a sua exigência pelo rigor e por uma incansável disposição de retomar seus trabalhos continuamente, com a finalidade de novos questionamentos, numa procura constante de uma base radical para o pensamento.

A obra, A Crise da Humanidade Europeia e a Filosofia, é considerada o testamento político de Edmund Husserl, conforme Stefan Strasser apud Zilles (2002, p. 43). É a sua fase de maturidade intelectual, do vitalismo historicista. É o testamento que confirma o espírito meticuloso de um pensador incansável e de um filósofo criterioso no aprendizado constante que se manifestou com o objetivo de instituir uma filosofia como ciência rigorosa, especialmente, diante da condição de fragilidade em que a mesma se encontrava nos tempos do filósofo.

O inconformismo de Husserl, sua atitude rigorosa de investigação, a agudez do seu espírito o tornavam distinto dos demais cientistas e pensadores. Entendia que o que estava em questão eram a vida, as vivências humanas e não cálculos, variantes expressões matemáticas ou um método que tratasse o homem com a mesma precisão das ciências naturais. A sua preocupação e pretensão de apresentar uma filosofia como ciência de rigor indicava a sua inquietação em não admitir que a vida humana ficasse à mercê de um projeto frágil, incoerente, de suporte teórico ou de teoria volátil e vulnerável (KELKEL e SCHÉRER, 1954).

Para Husserl, estava exposta a crise da humanidade, por conseguinte, a sua preocupação em evocar a herança cultural que originou e constituiu o alicerce comum da civilização ocidental. Seu posicionamento foi contra o desvio racionalista e, consequentemente, contra o irracionalismo. Assim expôs a sua concepção contra esse irracionalismo, denominado por ele de racionalismo ingênuo, presente nos séculos XVII e XVIII e ao qual fez oposição. Entendia as tarefas infinitas da razão humana e, ao mesmo tempo, era contrário ao objetivismo reinante nas ciências positivas, de forma marcante na psicologia, devido à consciência científica que se percebia do espírito enquanto espírito, impossível de ser captada pelo método e por técnicas dessas ciências.

Zilles (1996, p. 42 - 43) afirma que as palavras de Husserl ecoaram como uma profissão de fé: “e, portanto, as ideias são mais fortes que todas as forças empíricas". Para Husserl, a crise estava posta, não havia como negar a sua existência, por isso era um fato de que se deveria tomar consciência. Entender essa crise era perceber que o humano estava sendo esquecido ou afastado do projeto de ciência da modernidade. Ao mencionar a crise da humanidade, Zilles (2002, p. 43) esclarece que:

Esta crise refere-se às ciências europeias e ao homem europeu; refere-se à Europa como maneira espiritual, a Europa engloba manifestamente os domínios ingleses, os U.S.A., etc. Trata-se aqui de uma unidade de vida, de uma ação, de uma criação de ordem espiritual, incluindo todos os objetivos, os interesses, as preocupações e os esforços com as instituições e as organizações. Nelas atuam os indivíduos dentro das sociedades múltiplas de 
diferentes complexidades, em famílias, raças, nações, nas quais todos parecem estar interior e espiritualmente vinculados uns aos outros e, como disse, na unidade de uma estrutura espiritual.

Husserl considerava que o grande erro do objetivismo foi o esquecimento ou a desvalorização do subjetivo, ao substituir o mundo da vida pela natureza idealizada na linguagem dos símbolos. As teorias lógico-matemáticas impuseram o objetivismo a uma instância de ordem subjetiva que seria impossível alcançá-la por meio do método lógico-matemático.

O resgate do mundo da vida para Husserl só seria possível a partir do resgate do mundo humano. $\mathrm{O}$ anúncio de uma crise da humanidade europeia e a filosofia são o seu legado histórico e, ao mesmo tempo, uma ação política de contestar todo o universo científico imposto pelas ciências lógico-matemáticas.

$\mathrm{O}$ mundo estava em crise motivado pelo irracionalismo do objetivismo que forçava o desaparecimento da subjetividade, porque o progresso científico era explicado como única saída e única resposta para os problemas do mundo. Husserl observava com pesar esse fato, pois era uma confusão, uma ilusão essa interpretação que estudiosos e filósofos tomavam como escolha para a situação. Ele entendia que tal escolha não teria condições para solucionar o enigma constituído pelo conveniente mau uso da ciência, do esquecimento e do alheamento do mundo da vida. Como mencionado anteriormente, Husserl não desconsiderava a importância das ciências físicas e naturais; ele acreditava na função que cumpriam no plano objetivo do mundo físico e da natureza, porém advertia que a atividade que se desvenda por excelência como a mais ilustre do compromisso humano é o des-velar o mundo da vida (o Lebenswelt), o mundo humano. Para tanto, Husserl indicava a fenomenologia como um direcionamento para uma solução ou superação da crise que alienava o ser humano da sua origem, ou seja, da sua humanidade.

Husserl analisou, detidamente, o papel da crise e reforça que a mesma foi a extensão das ciências positivistas na sociedade moderna que fez o distanciamento do subjetivo no homem; por isso a sua veemente crítica ao reducionismo da racionalidade moderna que reduziu o conhecimento, o saber à mera esfera do técnico-científico. Ele entende que essa visão cientificista afastou e afasta a filosofia da sua função primeira; isto é, colocar a ciência como exclusivo e determinante elemento de compreensão do mundo. A racionalização da ciência, ou melhor, a razão técnico-científica torna-se pensamento único.

Nesse contexto, Pizzi (2006, p. 23) esclarece que

o fato de dar-se conta da crise gera também reações que indicam a busca de alternativas plausíveis. A partir do amplo leque da reflexão filosófica encontramos, nas últimas obras de Husserl, aspectos que identificam a crise das ciências modernas como expressão da cultura do final do século XIX e início do seguinte, furto do matematicismo do saber, atitude que afasta a razão dos problemas humanos. Diante disso, o autor insiste que é necessário reorientar a razão e as próprias ciências. Essa proposta objetiva aprofundar a discussão em torno da clássica relação entre Filosofia e racionalidade, cujo objetivo pretende apontar alternativas que possam ampliar o conceito de razão, até o ponto de reconhecer, no debate filosófico, a contribuição desse saber inerente ao Lebenswelt.

Desse modo surge sua proposta de um novo e rigoroso método que tivesse como base fundamental a valorização das pessoas no seu mundo da vida, situando-as como seres histórico-culturais, tendo como origem as vivências e as experiências do cotidiano. Para atender a sua proposta de "reumanização do homem", Edmund Husserl assumiu a fenomenologia como método, por meio do qual os homens, os sujeitos se descobrissem como seres no mundo em uma sociedade de sujeitos receptivos aos demais. 
Assim, a Fenomenologia restabelece a ideia de humanidade - originária da cultura grega nos seus primórdios -, ou melhor, restaura as certezas e as verdades que a compreensão humana não conseguira elaborar, devido à ação do positivismo que limitou a verdade no campo das ciências exatas. A verdade não se afasta da sua origem, como a compreende a maneira de visar da consciência. Neste aspecto, Morujão (2002, p. 331 - 332) confirma que:

\begin{abstract}
No sentido fenomenologicamente mais primitivo, revelou-se o mundo como mundo de coisas, fundamento de todos os outros; mundo perceptivo, englobante de todos os objetos possíveis da nossa experiência, terreno universal de cada uma das nossas experiências singulares. $\mathrm{O}$ retorno a este mundo é o retorno ao mundo da vida (Lebenswelt), ao mundo em que continuamente vivemos e que oferece o terreno para toda a atividade cognoscitiva e toda determinação científica, representando uma esfera infinita de ser válido. $\mathrm{O}$ Lebenswelt será o âmbito dos fenômenos puramente subjetivos, embora, não de puras faticidades de fluxos psicofísicos de dados sensuais, mas sim de fluxos espirituais que, nessa qualidade, necessariamente, exercem a função de constituírem estruturas significativas. Simplesmente, nenhuma filosofia, até hoje, elegeu como tema a esfera do subjetivo e, deste modo, realmente a descobriu; se a meditação filosófica, contudo, quiser realizar o seu sentido de fundamentação originária (Ursriftung) como ciência universal e ordenada a fundamentos últimos, necessariamente virá tirar essa esfera do anonimato.
\end{abstract}

A compreensão de que nenhuma filosofia assumira, até a atualidade, o objeto do conhecimento na dimensão subjetiva, torna a fenomenologia uma filosofia do humano. Segundo Van Breda apud Capalbo (1971, p. 39), "Husserl define a fenomenologia como uma direção do nosso olhar se voltando das realidades experimentadas para o caráter de serem experimentados".

Capalbo esclarece que Husserl almejava liberar o olhar humano para a análise do vivido. Nessa análise, o olhar humano visava de forma intencional e significativa ao objeto, sem ter em conta a sua presença. Assim como nesse intento expressivo o objeto se faz presente, ou melhor, quando esta intenção é preenchida pela presença do objeto, nós temos uma intuição. De acordo com Capalbo (1971, p. 39 - 40), a intuição é

o preenchimento (erfullung) da intenção. A consciência dessa intuição se chama evidência. Intuição e evidência são correlatas, e podem ser de tipos diversos, podem se dar em modos diversos. A intuição será, portanto, constituinte pois é graças ao preenchimento da intenção que ela irá constituir o objeto, tornando-o presente, e fazendo-o evidente. Para que se dê a intuição constituinte são necessários os seguintes elementos: a) hiléticos ou materiais: corresponderão aos dados sensíveis. Esses elementos se dão numa sequência temporal, e serão unificados, através da temporalidade, pelo eu transcendental, pelo eu puro. b) formais: correspondendo à intencionalidade que unificará os dados materiais e os significará. Essa intuição evidente é diferente da opinião puramente subjetiva. A evidência se dá quando a realidade visada está imediatamente presente à consciência; ela não necessita da mediação dos signos ou dos símbolos. Essa intuição é doadora, ela é um ver que constitui seus objetos. Conhecer é ver, é colocar-se à distância dos objetos, é dirigir-se a eles; ela não se une aos objetos nem os apossa, mas ela os visa progressivamente.

Essa intuição poderá se completar de duas formas: a) pela imaginação - quando a coisa, o objeto é dado em imagens; b) pela percepção ou pelo ato sensível ou hilé, (matéria do visado) quando for percebida ou, de forma categorial, quando a forma do visado for captada. Portanto, a consequência adquirida pelo preenchimento é ter uma significação completa, ou seja, resultante de uma significação vazia.

A significação vazia é a intenção significativa que não considera a presença do objeto; ao contrário, quando ela considera o objeto, ela é preenchida pela presença do mesmo, então ocorre uma intuição. Por isso, no fenômeno, a verdade se apresenta à consciência na totalidade, isto é, ela se faz presente e se mostra como constituinte e constituída de uma só 
coisa. Cada ideia acontece no todo e numa sequência contínua. Exemplo: quando se pensa em árvore, a ideia de árvore se faz no todo; a árvore intuída ou percebida aparece à consciência de forma completa; o sujeito não capta a raiz, o tronco, as folhas para formar a ideia de árvore; ela se fará presente como objeto total constituído na consciência. Mota (2006, p. 130) assevera que

a consciência como 'consciência de qualquer coisa', também é, de um certo modo, derivada de si mesma, fundada. Na medida em que o em si é apenas o correlato da consciência intencional igualmente esta lhe é correlativa, fundada nos objetos que funda. A consciência é unidade subjetiva de diversidades objetivas visadas e constituídas por si num habitus como atividade intencional, cujos objetos the aparecem assim como seus produtos, dos quais ela é a consciência (o conjunto no ato de coligir, o número no ato de enumerar, a parte da divisão, o predicado ou o 'estado de coisas' na predicação ou explicação duma percepção).

$\mathrm{Na}$ perspectiva de que a consciência é fundante, por isso mesmo analogamente fundada na percepção, a consciência que apreende as idealidades é uma consciência "fundada", isto é, organizada. Conforme Mota (2006, p. 131), "Na medida em que o seu 'fundamento' é uma intuição sensível - temporal -, o eu portador das verdades predicativas será elemesmo um eu temporal". Portanto, é um eu constituído no mundo da vida, "o solo 'natural' reduzido da consciência absoluta". Por isso, esse "solo" deve ser muito significativo, pois é nele que se fundamenta a verdade da consciência. Porém, se as coisas e os objetos são verdades da consciência, adentramos na significação ôntica da vida dos fenômenos humanos. Para Husserl, as ciências modernas não conseguiram atingir a dimensão de humanidade devido à simplificação do fenômeno humano a uma dimensão numérica, positivista $\mathrm{e}$ cartesiana de ver, apreender e conceber a humanidade, ou seja, o homem.
Na obra A Crise da Humanidade Europeia e a Filosofia, como já foi dito anteriormente, Husserl propõe uma volta ao mundo da vida; e reafirma, o mundo da vida é uma atitude experienciada e précientífica das coisas, ou melhor, é a atitude de "ir às coisas mesmas". Conforme Mota (2006) é uma atitude que as crianças, os ignaros e os primitivos têm e tiveram, isto é, o privilégio de serem donos de uma visão constituída apenas de uma sabedoria 'a priori', com uma "estrutura universal" mantendo-se e formando-se no seu próprio mundo e modos de devir, isto é, de vir a ser. É capacidade de tornarem-se seres dotados de idealidades, preenchidos pela atitude natural, porém eivados de significados no seu mundovida.

Com base nessa concepção, a ação da Fenomenologia será a de evidenciar a razão por meio da consciência humana, por meio das suas vivências, pelas experiências, pelas tradições e fragmentações de sentido que sugeriam não existir antes dela, porém lhe competiam, ou seja, eram seu objeto desde a sua genealogia.

Vincular o mundo da vida à consciência é extraí-lo da penumbra é tirá-lo da opacidade de uma realidade, em si estranha, e subordiná-lo à claridade da razão e ao domínio da liberdade. Diante da razão e da liberdade, o sentido não poderá perder-se na história, porém deverá tornar-se cônscio para refletir filosoficamente, bem como restabelecer de forma atuante o sentido da História. É fundamental perceber que o sentido não está dado de maneira antecipada; ele é a razão não aparente que se procura na experiência humana e na reflexão filosófica e científica sobre essa experiência. Portanto, o retorno à subjetividade constitui o retorno ao mundo, a priori, dado, isto é, ao mundo da vida, ao mundo subjetivo. O mundo-vida, a partir da perspectiva fenomenológica, expande-se em 
esperanças espirituais, apresenta um espaço para novas ideias e propicia possibilidades de constituição de um mundo novo. Essa ocorrência acontece, principalmente, devido ao fato de a Fenomenologia ser essencialmente provocadora do reexame dos problemas que, supostamente, já se apresentavam como resolvidos. A concepção fenomenológica provoca um novo olhar sobre os mesmos fatos, as mesmas coisas, os mesmos problemas, com atitude de reflexão, repensando, reelaborando, reconstruindo os dados fundamentais que estão intrinsecamente voltados para o mundo da vida.

Então, na perspectiva husserliana, o resgate do mundo da vida é a volta ao princípio de humanidade constante do ser humano. Ao perceber a sua dimensão de humanidade, o homem liberta seu espírito, princípio fundamental para o exercício do pensamento, isto é, do ato de pensar.

A libertação do espírito possibilitará ao ser humano compreender o mundo de forma dinâmica e mutável, e não de forma engessada por uma visão de mundo idealizado. Assim, possibilitará perceber os fundamentos utilizados pelo mau uso da ciência ou mesmo da razão e contribuir, em contrapartida, para a procura de uma humanidade plena, com a qual almeja o ser humano. É esta possibilidade de reflexão que a fenomenologia propõe ao exercitar, a partir do mundo da vida, um novo universo de compreensão, interpretação e "iluminação" que modificará a relação do sujeito com o mundo extraindo dele o melhor sentido. Por isso, para Husserl, a fenomenologia é a busca para o sentido da existência.

\section{A FENOMENOLOGIA E A FORMAÇÃO HUMANA}

Falar de Fenomenologia e a Formação Humana é um desafio, principalmente, em uma época cada vez mais marcada pela ausência do humano em que impera a tecnologia, o consumismo, o imediatismo, a impessoalidade, a exclusão e o poder do capital. É uma era marcada pela crise de civilização, crise de valores, crise política, crise social. Uma sociedade que valoriza mais o Ter que o Ser. Qual a contribuição da fenomenologia neste contexto quando se fala de ciência, formação, utopia e desencanto?

Para a fenomenologia, a formação humana se refere a uma ação de afirmação da humanização. Do nascimento biológico as mais diversas formas de socialização não são garantias de sua efetivação, é necessária a existência processual de orientação do ser humano para sua formação direcionada para o processo civilizatório. A temática da formação humana foi tema, em maio de 1935, da conferência que Husserl apresentou abordando $A$ crise $d a$ Humanidade Europeia e a filosofia. Período de crise em que a sociedade se encontrava e sofria as imposições do poder capitalista e nacionalistasocialista, as manifestações racistas e a perseguição que se tornaram uma realidade para as pessoas, principalmente, para os judeus no que se refere ao preconceito político, situação que na atualidade de certa forma vivenciamos com a exploração econômica, as guerras, as intolerâncias religiosas, políticas, de gênero, de raça e desrespeito as diversidades humanas.

A situação da Europa dividida pelos nacionalismos belicistas transformou o território europeu em campo de extrema violência, em que imperava a visão totalitarista que provocou o surgimento do nazifascismo; as ações de controle e poder sem limites que levaram a Itália, sob o comando 
de Benito Mussolini, e a Alemanha, com Adolf Hitler, aos atos da maior barbárie a que o mundo contemporâneo assistiu: genocídio, execuções sumárias, mutilações físicas, esterilização em massa, perseguições por raça, credo religioso, ideologia política, isolamentos e trabalho forçado em campos de concentração nazistas.

Registrou-se uma violação total dos direitos humanos, sobretudo os direitos das pessoas e grupos contrários ao regime nazista ou que representasse alguma divergência aos seus líderes e simpatizantes. Nesses grupos estavam inclusos trabalhadores urbanos e rurais, bem como suas lideranças e representantes de sindicatos de qualquer categoria profissional, mulheres, negros, judeus, outras etnias e minorias religiosas, crianças, adolescentes, idosos, professores e alunos universitários.

Contra essa barbárie, violação dos direitos e desvalorização da vida e existência humana, Husserl anuncia a crise da humanidade europeia, uma crise espiritual, em que o homem, que é racional e deveria usar a razão em benefício da humanidade, a utiliza contra o gênero humano. A razão que nega o humano é irracional, o que acontecia na Europa era a desumanização da sociedade em sentido literal. Estamos, portanto, segundo Husserl, diante de uma crise de civilização; crise espiritual do ente europeu; crise da Europa como ente cultural; crise negadora da dimensão humanizadora. É a identidade europeia inautêntica personificada no capitalismo, no socialismo ditatorial e outras formas de poder autoritárias que buscam preservar os interesses do capital, a manutenção do poder, a afirmação do espírito objetivista e cientificista, a manutenção da exclusão social, o consumismo, o individualismo e a banalidade da vida humana. É o processo de instrumentalização da razão que Husserl chama de objetivismo.

Essa racionalidade instaurou uma profunda crise na civilização europeia, assolada por guerras, preocupação desmedida com a acumulação de capital, profundas desigualdades sociais. Diante da catástrofe para a qual caminhava a Europa, Husserl se posiciona, conforme afirma Pelizzoli (2002, p. 24):

[...] a exposição de 1935 (Krisis...) é precisa e sintomática, revelando o que estaria no contraponto de toda busca da fenomenologia: crise. Crise da humanidade europeia, bem esboçada na catástrofe 'autofágica' de 1914 a 1917. Mas mesmo antes, afiguram-se pressentimentos, com os quais os filósofos, ao modo dos artistas, se envolvem in profundis, algo de um tremor e grande temor existencial e cultural - bem expresso no racismo e preconceitos variados, no purismo e racionalismos, que são como que pontos aglutinadores de reações por parte de uma humanidade que tenta desesperadamente se afirmar contra o seu estranhamento, sua dispersão, o seu outro.

Pelizzoli (2002, p. 25) ainda acentua que o pressentimento de Husserl era não só em relação ao presente, mas ao futuro da humanidade ocidental:

Assim [...] o que está em jogo, na verdade o presente e o futuro de toda a grande tradição do pensamento ocidental. [...] estamos submersos num dilúvio de propostas ingênuas e exaltadas de reformas. Para ele, está em questão não só o destino da filosofia, mas da Europa, da humanidade, na mediada em que a primeira é a sua raiz, seu centro, seu sentido teleológico último, o sentido que a razão tomou punho. Definitivamente, a flexibilidade e relativização paradigmática que se espraiava nas várias pulverizações dos cânones da racionalidade ocidental, abalando sua orientação, e, em especial, a ameaça dos irracionalismos, tudo assustava Husserl e era motivo para buscar uma superação e um resgate. Na verdade, trata-se de restaurar o sentido maior do progresso da razão, das luzes mesmas, expressas em especial no racionalismo e nas filosofias da consciência com base no cogito; o final da Crise [...] é sintomático, ao buscar resgatar o racionalismo de seu 'fracasso aparente'. A superação em jogo não se daria por um novo golpe de progresso técnico ou nova modalidade de cultura para o futuro, mas pelo retorno a uma instância mais originária de sentido, iniciando pela suspensão do objetivismo e naturalismo 
reinantes, que estavam pretensamente a solapar a instância do espírito.

$\mathrm{Na}$ expectativa de ver solapada toda a instância do espírito filosófico, diante do racionalismo excessivo, tecnicista e cientificista, que era uma forma de irracionalidade, Husserl busca restaurar o sentido maior do progresso da razão, das luzes mesmas, isto é, um retorno da razão à consciência com base no cogito humanizado. Era à volta ao sentido originário do pensar, contra o psicologismo, o empirismo, o naturalismo e o positivismo vazio de humanidade, ou seja, orientações teóricas voltadas somente para o progresso técnico e cientificista que impunham ao homem a cultura do tecnicismo, do cientificismo, burocratismo e capitalismo. Com esse espírito objetivista e pragmatista a filosofia se distanciou do lebenswelt, do mundo vivido, da atitude crítica e questionadora. É por isso que Husserl propõe que a filosofia e as ciências se voltem para as coisas mesmas, para o seu estado originário e antipredicativo, para apreender o seu verdadeiro sentido.

Husserl, na conferência de 1936, considerada o seu verdadeiro testamento filosófico - a Crise das Ciências Europeias e a Fenomenologia Transcendental, afirmava (2002, p. 65):

Nesta conferência quero ousar a tentativa de suscitar um novo interesse para o tão frequentemente tratado tema da crise europeia, desenvolvendo a ideia histórico-filosófico (ou o sentido teleológico) da humanidade europeia. Ao expor a função essencial que, neste sentido, tem a exercer a filosofia e suas ramificações, que são nossas ciências, a crise europeia também ganhará uma nova elucidação.

Para Husserl, era inconcebível que a Europa, berço da razão crítica e humanizadora desde os gregos antigos, negasse a dimensão da vida como estava ocorrendo. Por isso, Husserl (2002, p. 66) alertava para a importância de dirigir-se o olhar "da corporeidade humana para a espiritualidade humana". A filosofia e as ciências, ao se distanciarem do lebenswelt, se distanciaram do mundo humano, se fecharam no mundo das doutrinas, mundo das interpretações, do já dito e esqueceu-se de sua finalidade. Portanto, a crise da humanidade europeia era uma crise do pensar e da orientação da ação, da intervenção do homem no mundo.

As nações europeias estão enfermas. Diz-se que a própria Europa está em uma crise. Não faltam curandeiros. Estamos submersos num verdadeiro dilúvio de propostas ingênuas e exaltadas de reforma. Mas por que aqui as ciências do espírito, tão ricamente desenvolvidas, não prestam o serviço que as ciências da natureza cumprem excelentemente em sua esfera? Aqueles que estão familiarizados com o espírito das ciências modernas poderão responder sem dificuldade: a grandeza das ciências da natureza consiste em elas não se conformarem com uma empiria sensível porque, para elas, toda a descrição da natureza só é uma passagem metódica para a explicação exata, em último lugar, físico-química. Os mesmos opinam que as ciências 'meramente descritivas' nos prendem às finitudes do mundo circundante terreno. Mas a ciência da natureza matemáticoexata abrange, com seu método, as infinitudes em sua efetividades (in ihrer Wirklichkeiten) e possibilidades reais (und realen Möglich-keiten).

Nesse cenário de crise e de enfermidade, como a considerava, o pensador reagiu e teceu severas críticas ao modelo e às concepções de ciências vigentes. Com base nessa concepção, a ação da Fenomenologia será a de evidenciar a razão por meio das suas vivências, experiências, tradições. Vincular o mundo da vida à consciência é extraí-lo da penumbra, é tirá-lo da opacidade de uma realidade, em si estranha, e subordiná-lo à claridade da razão e ao domínio da liberdade. Diante da razão e da liberdade, o sentido não poderá perder-se na história, porém deverá tornar-se cônscio para refletir filosoficamente, bem como restabelecer o sentido da História. É fundamental perceber que o sentido não está dado de 
maneira antecipada; ele é a razão não aparente que se procura na experiência humana e na reflexão filosófica e científica sobre essa experiência. Portanto, o retorno à subjetividade constitui o retorno ao mundo, o a priori, o dado, isto é, ao mundo da vida, ao mundo subjetivo. $\mathrm{O}$ mundo-vida, a partir da perspectiva fenomenológica, expande-se em esperanças espirituais, apresenta um espaço para novas ideias e propicia possibilidades de constituição de um mundo novo. Essa ocorrência acontece, principalmente, devido ao fato de a Fenomenologia ser essencialmente provocadora do reexame dos problemas que, supostamente, já se apresentavam como resolvidos. A concepção fenomenológica provoca um novo olhar sobre os mesmos fatos, as mesmas coisas, os mesmos problemas, com atitude de reflexão, repensando, reelaborando, reconstruindo os dados fundamentais que estão intrinsecamente voltados para o mundo da vida.

Então, na perspectiva husserliana, o resgate do mundo da vida é à volta ao princípio de humanidade constante do ser humano. Ao perceber a sua dimensão de humanidade, o homem liberta seu espírito, princípio fundamental para o exercício do pensamento, isto é, do ato de pensar.

A atitude fenomenológica possibilitará ao ser humano compreender o mundo de forma dinâmica e mutável, e não de forma engessada por uma visão de mundo idealizada. Assim, possibilitará perceber os fundamentos utilizados pelo mau uso da ciência, da técnica, da razão e do capital e contribuir, em contrapartida, para a afirmação da humanidade plena, com a qual almeja o ser humano. É esta possibilidade de reflexão que a fenomenologia propõe ao exercitar, a partir do mundo da vida, um novo universo de compreensão, interpretação e orientação que modificará a relação do sujeito com o mundo. Por isso, para Husserl, a fenomenologia é a busca para o sentido da existência.

Diante do exposto, podemos perceber a visão de educação enquanto formação humana para Husserl, que passa pelo rigor intelectual e estende-se ao mundo-vida, isto é, à sua dimensão acadêmica e humana. O pensamento de Husserl apresenta um caráter pedagógico, formativo, pois expressa tanto uma preocupação com o rigor e o método, quanto com a questão do humano. A vida de Husserl apresenta posições fundamentais sobre o homem, a razão e a vida, as quais o levaram ao enfrentamento do regime nazista que anulava o ser humano em defesa de um ideal totalitário.

O combate ao nazismo, ao fascismo e ao capitalismo feito por Husserl foi de denúncia e resistência ao mal que estas formas de poder causavam à humanidade. Ao destituir o homem da sua condição de ser, da sua capacidade de pensar e refletir a partir da sua vivência, da sua experiência, do seu mundo-vida, estas formas de poder negavam ao homem a sua condição essencial para a existência: a sua humanidade. Husserl instaura, então, uma dimensão pedagógica de resistência do sujeito ao mundo de banalização da existência que se fazia presente, naquele momento histórico.

A ação de resistência ao ideal totalitário é um retorno do humano ao mundo da vida. Era um apelo à razão filosófica, um apelo à capacidade do homem de se orientar pela sua consciência interna e não por uma consciência externa, ou seja, perceber o mundo a partir da sua razão e não pela razão imposta por uma visão totalitária. É uma ação pedagógica de busca da verdade é o "conhecer-te a ti mesmo", lema do templo de Delfos, na Grécia antiga. Essa busca se faz pela reflexão e ação, é uma volta ao que foi pensado de forma irrefletida para orientar a intervenção humana. 
Daí o surgimento do lema husserliano à volta "às coisas mesmas" por meio de uma consciência que visa a algo, pelo caráter da intencionalidade de que "toda consciência é consciência de alguma coisa". Esta é uma dimensão pedagógica fundamental para o processo ensino-aprendizagem, dada a intencionalidade em direcionar a consciência para essa finalidade.

$\mathrm{O}$ ato de enfrentamento e resistência de Husserl apresentava a possibilidade de o homem resistir ao pensamento imposto, à razão totalitária, e tornar-se sujeito da sua ação, da sua condição de ser humano. Conforme Kelkel e Schérer (1954) e Merleau-Ponty (1999), Husserl se preocupava com a questão do ser e como o ser compreendia a realidade dada pela consciência; porém, o seu pensamento apresentava um caráter formativo, pedagógico radical (ir à origem) e rigoroso, fundamentado pelo método fenomenológico.

Como condição de revelação do mundo, a fenomenologia tem como tarefa revelar o mistério deste e o mistério da razão. A partir do resgate da categoria de Lebenswelt, é admissível restaurar os diferentes mundos: docente e discente, sujeito e consciência, razão e emoção, objetivo e subjetivo. Compreender o significado de cada um e contribuir para um projeto de educação orgânico e coerente com as aspirações de formação humana voltada para a autonomia, logo, significativo e emancipador. Por isso a categoria Lebenswelt é uma referência importante de análise e imprescindível para Husserl na constituição do pensamento fenomenológico e do pensamento pedagógico em toda sua obra. Desta forma, o pensamento de Edmund Husserl ratifica a sua importância para o conhecimento humano na idade contemporânea.
O mundo globalizado neoliberal se mostra a cada dia mais tecnicista e cientificista, esvaziado de humanidade, tal como a Europa em que Husserl viveu. No presente, em nome do capital, de uma ciência e uma visão tecnológica, estamos cada vez mais distantes do humano, da dimensão ontológica do existir. Estamos em crise, ou seja, vivenciamos o aprofundamento da crise da humanidade europeia, que é a crise da humanidade ocidental, isto é, a crise da desumanização.

Vivemos, novamente, um racionalismo tecnológico que leva o homem à irracionalidade em relação ao ser e ao existir, enquanto pessoa, como humanidade. Estamos perdendo a razão, a racionalidade como condição humana de ser e de existir para o desenvolvimento de um irracionalismo vazio, calculista, preso a valores fúteis e externos à vida, distantes fisicamente e próximos pela tecnologia. Porém, esse mesmo homem sente-se angustiado e perplexo diante da existência, movido por ganância econômica, poder político e cada vez mais individualista e solitário em sua humanidade.

Portanto, diante do exposto, a partir da fenomenologia podemos compreender o processo de educação e formação humana e o processo de ensino deve ser formativo não na medida em que "conforma" ou molda, mas no sentido em que indica uma trilha de cultura humana já percorrida e que deve abrir para as possibilidades de novas trilhas. Aí a ideia de formação carrega o sentido de fazer-se, de construir-se nas e a partir das relações humanas já dadas e em processo. Em devir. O empreendimento aqui principiado é uma solicitação para continuar a filosofar a respeito. Um convite aos professores, estudantes e as pessoas em geral a refletir fenomenologicamente sobre as ações do homem no mundo. No momento histórico em que vivemos marcados pelo drama de milhões de refugiados que colocam em 
risco a própria vida para fugir das guerras, da intolerância e da fome, assim como a escalada cada vez maior da acumulação do capital às custas da miséria, da fome, do desemprego, e a falta de ética na gestão da coisa pública, talvez seja uma importante contribuição para a educação problematizar os atuais problemas enfrentados pela humanidade.

Todos os autores declararam não haver qualquer potencial conflito de interesses referente a este artigo.

\section{REFERÊNCIAS}

BICUDO, Maria Aparecida Viggiani; CAPELLETTI, Isabel Franchi (Orgs.). Fenomenologia: uma visão abrangente da educação. São Paulo: Olho d'água, 1999.

CAPALBO, Creusa. Fenomenologia e Ciências Humanas. $3^{\text {a }}$ edição revista e aumentada. Londrina: Ed. UEL, 1996.

CAPALBO, Creusa. A Fenomenologia Segundo Husserl. In: Revista Brasileira de Filosofia. São Paulo: Instituto Brasileiro de Filosofia, 1971, p. 39 46. vol. XXI Fasc. 81.

FABRI, Marcelo. A atualidade da ética husserliana. Princípios, Natal, vol. 12, no 17 - 18, jan./dez. 2005, p. $157-172$.

HEIDEGGER, Martin. Todos nós... ninguém: um enfoque fenomenológico do social. Apresentação, introdução, notas e epílogo Dr. Sólon Spanoudis; tradução e comentário Dulce Mara Critelli. São Paulo: Moraes, 1989.

HUSSERL, Edmund. A Crise da Humanidade Europeia e a Filosofia; introdução e tradução de Urbano Zilles. - $2^{\mathrm{a}}$ ed. Porto Alegre: EDIPUCRS, 2002 (Coleção filosofia vol. 41).

HUSSERL, Edmund. Meditações Cartesianas: Introdução à Fenomenologia. Porto, Portugal: Edições Rés, 2000.

HUSSERL, Edmund. A Ideia da Fenomenologia. Tradução: Artur Morão. Lisboa: Edições 70, 1990.
HUSSERL, Edmund. Investigações lógicas: sexta investigação - elementos de uma elucidação do conhecimento. Tradução: Zelijko Loparik; Andréa Maria Altino Campos Loparik. São Paulo: Nova Cultural, 1985

KELKEL, L. Arion; SCHÉRER, René. Husserl. Tradução de Joaquim João Coelho Rosa Lisboa: Edições 70, 1954.

MARTIN, Javier San. Epojé y ensimismamiento. El comienzo de la filosofía. Phainomenon. Boletim Ibérico de Fenomenologia. Número 7, 2003.

MARTINS, Joel. Um enfoque fenomenológico do currículo: educação como poiéses. In: ESPÓSITO, Vitória Helena Cunha (Org.), São Paulo: Cortez, 1992.

MERLEAU-PONTY, Maurice. Fenomenologia da Percepção. Trad. Carlos Alberto Ribeiro de Moura, $2^{\text {a }}$ ed. são Paulo: Martins Fontes, 1999.

MORUJÃO, Alexandre F. Estudos Filosóficos. Imprensa Nacional - Casa da Moeda, Lisboa, 2002 (Coleção: Estudos Gerais - Série Universitária).

MOTA, Pedro. De Husserl a Merleau-Ponty e Mikel Dufrenne: Fenomenologia e Estética: reflexão crítica. Prometeu, 3 - Edições Ecopy, Porto, PT, 2006.

PELIZZOLI, Marcelo Luiz. O eu e a indiferença: Husserl e Heidegger. Porto Alegre: EDIPUCRS, 2002 (Coleção filosofia vol. 150).

PIZZI, Jovino. O mundo da vida: Husserl e Habermas. Ijuí: Ed. Inijuí, 2006 - (Coleção filosofia 11).

ZILLES, Urbano. A Fenomenologia Husserliana como Método Radical. In: EDMUND HUSSERL: A Crise da Humanidade Europeia e a Filosofia, ed. Porto Alegre; EDPUCRS, 2002. vol. 41 (Coleção Filosofia).

ZILLES, Urbano. Teoria do conhecimento. Porto Alegre: EDIPUCRS, 1996.

ZITKOSKI, Jaime José. O Método Fenomenológico de Husserl. Porto Alegre: EDIPUCRS, 1994 (Coleção Filosofia: vol. 12). 